\title{
AS INDIVIDUALIDADES POPULARES: análise de setores urbanos no Chile ${ }^{1}$
}

\author{
POPULAR INDIVIDUALITIES: \\ an analysis of urban sectors in Chile
}

\author{
Kathya Araujo* \\ Danilo Martuccelli ${ }^{* *}$
}

(Tradução de Rodrigo Vieira de Assis ${ }^{* *}$ )

\begin{abstract}
Resumo
As ciências sociais em geral propuseram leituras das classes populares e do popular que tenderam a minimizar a existência de formas de individualidade em seu seio, dando lugar a visões altamente coletivistas de seus membros. Com base em duas investigações empíricas de tipo qualitativo sobre o caso do Chile, realizadas mediante entrevistas semiestruturadas e técnicas grupais, este artigo discute que, sem desconhecer a comunidade de experiências observável entre seus membros, é possível dar conta de certos processos individualizadores específicos nesse grupo social. Frente às numerosas adversidades de sua existência em um contexto de alta instabilidade posicional e de exigência de hiperatuação, os membros dos setores populares urbanos tendem a afirmar a sua individualidade a partir de três dimensões: a força do caráter; a habilidade e o sentido de oportunidade; e o prazer e a irreverência humorística.
\end{abstract}

Palavras-chave: Classes populares. Setores urbanos. Individualidades populares. Chile.

\begin{abstract}
The social sciences have in general proposed readings of popular and popular classes tending to minimize the existence of forms of individuality in their midst, placing highly collectivist visions of their members. Based on two qualitative empirical researches about Chile, performed by semi-structured interviews and focal groups, this article argues that, without uncognizing the set of noticeable experiences among their members, it is possible to account
\end{abstract}

1 Publicado pela primeira vez como Las individualidades populares: análisis de sectores urbanos en Chile, em Latin American Research Review (LARR), v. 50, n. 2, p. 86-106, 2015. Agradecemos aos autores a permissão para publicação no Dossiê Sociologias em Escala Individual da Revista de Ciências Sociais Política e Trabalho.

* Professora e pesquisadora do Instituto de Estudos Avançados (IDEA) da Universidade de Santiago de Chile (USA$\mathrm{CH}$ ). Suas principais áreas de interesse atuais em sociologia são as normas, processos de individuação e configuração de sujeitos, teoria social e psicanálise (escola francesa). Publicou mais de quinze livros, entre os quais, Dignos de su arte (2009), Habitar lo social (2009), Desafíos comunes (com Danilo Martuccelli, 2 volumes, 2012), El miedo a los subordinados (2016) e, como editora, ¿Se acata pero no se cumple? (2009) e Legitimization in World Society (com Aldo Mascareño, 2012).

** Professor de sociologia da Universidade Paris-Descartes, da Faculdade de Ciências Humanas e Sociais (Sorbonne) e da Universidade Diego Portales (UDP). Suas principais áreas de interesse são teoria social, sociologia da individuação e sociologia política. Publicou inúmeros livros, entre os quais se destacam Sociologies de la modernité (1999), Grammaires de l'individu (2002), La consistance du social (2005), Forgé par l'épreuve (2006), La Société singulariste (2010), Les sociétés et l'impossible (2014) e La condition sociale moderne (2017). Como coautor com François Dubet, publicou A lécole (1996); com Maristella Svampa, La plaza vacía (1997), com Bernardo Sorj, El desafío latinoamericano (2008); e com Kathya Araujo, Desafios comunes (2 volumes, 2012).

${ }^{* * *}$ Doutorando em Sociologia, Instituto de Estudos Sociais e Políticos da Universidade do Estado do Rio de Janeiro (IESP-UERJ) / Brasil. Professor Substituto do Departamento de Ciências Sociais da Universidade Federal Rural de Pernambuco (UFRPE) / Brasil. Autor de Para uma sociologia das visões de mundo: cultura, pensamento e práticas sociais (Editora Appris, no prelo). É membro do Sociofilo: (co)laboratório de teoria social (IFCS/UFRJ). E-mail: rvassis@outlook.com 
certain specific individualizing processes in this social group. Faced with many adversities in their existence in a context of high positional instability and of hyperactivity requirement, the members of urban popular sectors tend to assert their individuality from three dimensions: the strengh of character; the ability and the sense of opportunity; and the pleasure and the humorous irreverence.

Keywords: Popular classes. Urban sectors. Popular individualities. Chile.

As ciências sociais produziram leituras das classes populares e do popular que, em geral, tenderam a minimizar a existência de formas de individualidade em seu seio, dando lugar a visões altamente coletivistas e homogêneas de todos os seus membros. Uma atitude que curiosamente assume, com escassa discussão, um dos grandes preconceitos de classe que recai sobre os sujeitos populares. No presente artigo, com base nos resultados de duas investigações empíricas ${ }^{2}$, proporemos, ao contrário, uma aproximação a esses setores enfatizando o caráter comum das experiências sociais de seus membros e as orientações profundamente individualistas que estas mesmas situações engendram.

Desenvolveremos o argumento em várias etapas. Em um primeiro momento, evocaremos brevemente as principais armadilhas sociológicas presentes no estudo do popular e suas consequências no estudo dos indivíduos desse grupo social, com o exclusivo fim de delinear uma noção que permita superá-las, que denominaremos de individualidade popular. Dado que a plena compreensão desta só é possível em relação a um conjunto de grandes transformações estruturais, em um segundo momento, nós nos deteremos brevemente a apresentar o caso do Chile nessa perspectiva. As três seções seguintes estarão consagradas a discutir três dimensões a partir das quais se afirma e se expressa essa individualidade popular na sociedade chilena: a força do caráter; a habilidade e o sentido de oportunidade; e o prazer e a irreverência humorística.

\footnotetext{
2 A primeira é um estudo sobre o processo de individuação na sociedade chilena, baseado na realização de noventa e seis entrevistas semiestruturadas nas cidades de Santiago, Conceição e Valparaíso (PROJETO FONDECYT No 1085006). As entrevistas estiveram destinadas a identificar, a partir das experiências dos indivíduos, os desafios sociais que enfrentam, a hierarquização que fazem deles e as modalidades de individuação a que são impulsionados para enfrentá-los. Este texto se baseia na análise das quarenta entrevistas correspondentes a homens e mulheres, entre 30 e 55 anos, dos setores populares urbanos da região metropolitana. A segunda é um estudo destinado a identificar as formas de exercício da autoridade e as razões para a obediência tanto no trabalho como na família no contexto da democratização social no Chile (PROJETO FONDECYT No 1110733). Foram realizadas entrevistas semiestruturadas e grupos de conversação-dramatização com homens e mulheres entre 30 e 55 anos. Para este artigo, utilizamos a análise de 16 entrevistas e seis grupos correspondentes aos setores populares. Todos os entrevistados, em ambas as investigações, pertencem essencialmente ao chamado setor D, mas também em fronteira de C3. Para caracterizar a posição social dos entrevistados consideramos profissão, bairro de residência, trajetória escolar e autopercepção. Nota do Tradutor (NT): os setores D e C3 indicados pelos autores como o universo em que estão situados os indivíduos analisados no Chile corresponderia, no Brasil, aos setores populares que foram, nas últimas décadas, objeto de intensa discussão no debate econômico, sociológico e político nacional, isto é, aos previamente pobres e às classes populares ascendentes: uma classe trabalhadora precarizada de sujeitos que percebem a si mesmos como batalhadores.
} 


\section{Dificuldades no estudo do popular}

O estudo do popular se situa de imediato em um conjunto reiterativo de três dificuldades teóricas e metodológicas. A primeira concerne à definição mesma do que se entende por "classes populares", uma caracterização que é, obviamente, mais frágil do que outras designações de classe como trabalhadores ou empregados, assalariados ou trabalhadores independentes, sendo que tende muitas vezes a associar sob uma designação comum membros destes diferentes grupos sociais (SCHWARTZ, 2011). Na América Latina, esta dificuldade é ainda mais aguda desde que foram adicionadas discussões e diferenciações suplementares em torno dos "marginais", dos trabalhadores "informais", das "classes subalternas" ou, de maneira especialmente aguda mais recentemente, dos "pobres", cada uma delas sublinhando a heterogeneidade interna das classes populares.

Todavia e indo além, algo é constante e central no uso do termo classes populares: apesar de suas diferenças, trata-se sempre de estabelecer um vínculo entre uma posição socioeconômica e uma atitude sociocultural, uma articulação cuja vigência resiste, no caso chileno, tanto à generalização de categorias sociais próprias às técnicas de mercado como à extensão do sentimento de serem membros das classes médias (BAROZET; ESPINOZA, 2009). Com efeito, como muitos estudos qualitativos mostram, os atores tendem a se autoposicionar como membros das classes populares em função de sua profissão, de sua renda, do seu bairro de residência, de sua trajetória escolar, mas também com base em traços fenotípicos ou atitudes culturais (ARAUJO, 2009, 2010).

A segunda dificuldade concerne à natureza mesma da "cultura popular", seja interpretada como uma cultura dominada (definida pela coerção ou déficit), seja, ao contrário, que o "povo" esteja definido a partir de suas virtudes culturais de resistência e alteridade. Trata-se de um tema particularmente ativo na sociologia francesa, devido significativamente à herança controvertida do trabalho de Pierre Bourdieu (1979), como na sociologia britânica, por causa da forte impressão em seu seio da tradição classista.

Em ambos os casos, por vias distintas, aparece uma forte dicotomia entre uma leitura "miserabilista" e uma interpretação "populista" (GRIGNON; PASSERON, 1989); entre aqueles que só consideram a cultura popular desde seu déficit de legitimidade em relação à cultura das classes superiores, inclusive em nível de seus códigos linguísticos (BERNSTEIN, 1975), e os que, em reação, esforçam-se em ler a cultura popular de maneira autônoma, negando, para seguir o mesmo exemplo, que a língua popular, apesar de sua especificidade oral, suponha diferenças de nível cognitivo ou intelectual (LABOV, 1976).

$\mathrm{Na}$ América Latina, também a noção de cultura popular tem sido particularmente debatida pelo caráter essencialista que tendia a cobrar em uma leitura que apoia a autonomia e a resistência como atributos incontestáveis da classe popular (GARCÍA CANCLINI, 1990). Ela, ainda que presente nos estudos de consumo cultural (CATALÁN; TORCHE, 2005), toma principalmente uma expressão bem mais política, seja através de sua associação explícita com 
os regimes nacional-populares, sobretudo, no marco do peronismo (GERMANI, 1962; JAMES, 1990; MARTUCCELLI; SVAMPA, 1997; LACLAU, 2005), seja sob a forma de um elogio da iniciativa propriamente popular (SOTO, 1986; FRANCO, 1991; LAVÍN, 1987).

A terceira grande dificuldade no estudo do popular concerne aos estereótipos populares, algo muito presente, por exemplo, nos estudos de Oscar Lewis (1982) sobre a "cultura da pobreza”. Nesses trabalhos, a tentação é reduzir os membros das classes populares em estereótipos coletivos: um aspecto observável em estudos que, concentrando-se, por exemplo, na cultura, na identidade, nas tradições ideológicas e até mesmo em traços idiossincráticos, identificam tipos de individualidade popular sob a forma de grandes caracteres nacionais ou morais.

No Chile, podem ser encontrados ecos desse tipo de análise nos estudos que a tradição costumbrista $^{3}$ fez dos membros dos setores populares em termos de "psicologia nacional" ou de "caracteres" (GUTIÉRREZ, 2010) e, inclusive, nas remanescências de alguns de seus traços na denominada "cultura da decência" (MARTíNEZ; PALACIOS, 1996). Estudos, em particular os primeiros, que, em geral, propuseram representações nas quais não somente se desfoca toda característica individual em benefício de arquétipos coletivos, mas que também se exclui curiosamente toda variação histórica a estes modelos. Para este caso, Larraín (2001) mostrou como foram forjados estereótipos do popular que, uma vez consolidados, terminaram por cristalizar a ideia de uma "alma popular" (introversão, tristeza, presentismo) cujas raízes imemoriais a tornariam estranhamente insensível à história do presente.

As três grandes dificuldades analíticas que chegamos a evocar no estudo do popular não concerne especificamente a análise dos indivíduos desse grupo social. Cada uma delas, porém, caracteriza-se ora por negar, ora por dificultar o estudo da individualidade de seus membros.

\section{Como apreender as individualidades populares?}

Tendo evocado essas três grandes dificuldades, resta-se perguntar: é possível propor uma interpretação do popular que consiga evitá-las e que permita, sobretudo, dar conta analiticamente das especificidades de seus membros? Para esboçar uma resposta positiva a esta pergunta, proporemos a noção de individualidade popular. A noção, construída indutivamente a partir de um importante material qualitativo, busca propor uma articulação entre as estruturas e as experiências, no que pode ser chamado de nível mesossociológico de análise. Nesse sentido, a noção se diferencia, por um lado, daqueles trabalhos que estudam o popular a partir das grandes figuras macrossociais do sujeito ou da identidade popular (sublinhando usualmente em excesso as homogeneidades intergrupais); e, por outro lado, de trabalhos que intentam dar conta da singularidade dos atores populares unicamente como uma consequência idiossincrática de uma série altamente personalizada de eventos biográficos (ou disposicionais).

3 NT: Um tipo de interpretação pictórica ou literária da vida cotidiana, presente, sobretudo, no cenário hispânico do século XIX. 
Para perfilar a noção de individualidade popular a este nível mesossociológico, nos apoiaremos - os recriando - em um conjunto díspare de estudos que, há décadas, intentaram romper com as três grandes dificuldades mencionadas (o estrito posicionamento de classe dos setores populares; a dicotomia entre cultura legítima e dominada; o confinamento de todos os seus membros em uma cultura comum estereotipada e homogênea).

Em primeiro lugar, esse estudo das individualidades populares se insere na família de trabalhos que sublinham a autonomia cultural relativa dos setores populares e, portanto, a existência de atitudes específicas entre seus membros em relação à construção de um sentido "próprio" do mundo. Há mais de cinquenta anos, os cultural studies da escola de Birmingham e, em particular, o trabalho pioneiro de Richard Hoggart $(1957,1988)$ - impuseram a visão de uma cultura popular com uma forte autonomia simbólica. Embora Hoggart não tenha negado, nem negligenciado, a referência à "outra" cultura - os burgueses -, não fez desta relação a chave interpretativa da cultura popular.

É o reconhecimento desta autonomia cultural relativa que permite o estudo das práticas culturais populares em si mesmas, privilegiando, por exemplo, a valorização das formas sensíveis da vida social da "gente de pouco" para retomar a expressão de Pierre Sansot (1991), a valorização específica que os setores populares fazem do lar e de certos bens de consumo (SCHWARTZ, 1990) ou de hobbies ou ocupações específicas (por exemplo, jardinagem, construção) que efetuam fora do lugar de trabalho, mas que mantém relação com ele (WEBER, 1989). Em suma, a partir desta dimensão se trata, sobretudo, de sublinhar o que de específico em relação a outros grupos sociais tem a individualidade popular.

Em segundo lugar, e neste ponto acentuando o afirmado por certas perspectivas, o estudo das individualidades populares faz eco da necessidade de rechaçar toda reificação "da" cultura dos setores populares em benefício de orientações normativas indissociáveis da experiência social e histórica de seus membros. Todo traço "da" cultura popular deve passar pelo filtro das experiências sociais, o que lhe outorga uma forte historicidade. É assim como, por exemplo, mas central para nosso argumento, é preciso relativizar a observação feita no seio das classes trabalhadoras e populares europeias dos anos sessenta e setenta em que se observou um predomínio "na" cultura popular do valor do coletivo sobre o individual. Isso não é um traço atemporal das classes populares: foi uma orientação cultural fruto de uma experiência política e social particular (consciência de classe, partidos políticos de classe, forte comunidade de estilos de vida). No caso inglês, assim, esta orientação normativa se construiu e se manteve durante décadas ao calor da consciência histórica em que nessa sociedade foi forjada a classe trabalhadora (THOMPSON, 1988); em outros países, essa mesma orientação se apoiou melhor em um "trabalhismo" identitário (VERRET; CREUSEN, 1995). Nesse segundo registro, dar conta das individualidades populares supõe, sem prejuízo do que corresponde à noção de cultura popular, compreender suas características a partir da forte porosidade observável das orientações normativas em relação às experiências sociais (ARAUJO, 2009). 
Em terceiro lugar, o reconhecimento das individualidades populares convida a sublinhar e radicalizar a existência de iniciativas e atitudes alternativas que não podem se associar inteiramente nem com a resistência nem com o conformismo (MARTUCCELLI, 2001). Neste sentido, o estudo das individualidades populares requer prolongar a reflexão que, em geral em

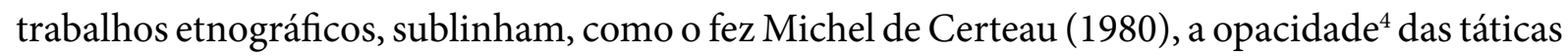
populares para "resistir" a partir da vida cotidiana à imposição de modelos culturais dominantes, ou a opacidade de maneiras tendenciosas e distintivas em que os membros dos setores populares falam sobre política em claro contraste - mas nem sempre conscientemente - como outros grupos sociais fazem (ELIASOPH, 1998). Uma atitude politicamente inclassificável e também visível na atração que os membros dos setores populares têm pelos fatos diversos (faits divers), os "acidentes", o "azar", mesmo para o sórdido e o macabro, abundantes na denominada imprensa amarela, que denota sem dúvida sua posição ambivalente e em homologia com a fragilidade de suas experiências de vida (DUBIED; LITS, 1999; GOULAT, 2010). Em muitas, mas não em todas as suas práticas, as individualidades populares, e é uma de suas características, ao mesmo tempo, coletiva e singular, opõem-se sem consciência expressa a outros modos culturais.

Em resumo: o estudo das individualidades populares e sua característica mesossociológica se desprende destes três fatores: (1) sua autonomia cultural relativa permite compreender que se seus membros compartilham orientações culturais de mais ou menos forte especificidade grupal, isto não os impede de compartilhar, ao mesmo tempo, elementos da cultura mainstream; (2) a autonomia cultural relativa das orientações normativas desse grupo social devem ser sempre interpretadas a partir de sua natureza histórica, isto é, é preciso se perguntar pela experiência social efetiva, coletiva e individual, que as produzem, mantêm ou a transformam; (3) finalmente, os dois fatores anteriores devem ser entendidos como elementos de uma atitude que proporciona a seus membros chaves singulares de compreensão tanto de situações como de pessoas e que é, por estranho que pareça, tudo de uma vez: uma atitude de resignação, de conformismo, de tomada de distância e de resistência.

A noção de individualidade popular aponta, pois, a descrever a existência de uma experiência social e posicional comum entre seus membros; remete, dentro de uma evidente continuidade, a acentuação histórica de certas tendências de individualização neste grupo social nas últimas décadas; e, por último, interessa-se pelas variações intragrupais e interpessoais de seus membros. Vale dizer que as individualidades em questão, sem que em nenhum momento se denegue seu aspecto coletivo, permitem declinações singulares na medida em que estão constantemente abertas à mudança e à revisão histórica e experiencial.

No caso do Chile, a individualidade popular na atualidade se caracteriza por três traços não únicos, mas sim especialmente salientes: uma valorização particular da força pessoal, um elogio afirmado da habilidade e o uso das oportunidades e uma atitude gozadora diante da

4 NT: Claroescuro no original espanhol. Na tradução optou-se pelo termo opacidade como equivalente, em português, ao sentido mais preciso dado pelos autores à expressão. 
existência. Cada um desses traços, como veremos, supõe uma autonomia cultural relativa, é o fruto de experiências sociais, históricas e específicas, delata uma iniciativa prática diante do mundo, às vezes de adaptação e rechaço, e permite dar conta da modalidade dual das individualidades populares - afirmando seu duplo caráter de experiências comuns e individuais.

Porém, antes de discutir em detalhes as formas específicas da individualidade nos setores populares urbanos, nós nos deteremos a dar conta brevemente, a partir de nossos resultados de pesquisa, de um conjunto de importantes transformações estruturais que os indivíduos percebem como impulsos ativos à afirmação de suas individualidades na sociedade chilena.

\section{Empurrões estruturais à individualidade}

Segundo nossos resultados, os indivíduos consideram que, nas últimas décadas, a sociedade chilena foi o teatro de duas grandes revoluções 5 . Por um lado, um conjunto de transformações associadas à virada para o neoliberalismo efetuada nos anos setenta, tanto em um plano político como econômico. Com a transformação dos princípios da proteção social, a privatização da educação, a previsão social e a saúde, e o consumo e o crédito convertidos em elementos estruturantes das relações sociais e da vida pessoal, difunde-se a imagem de uma sociedade perfeitamente móvel e competitiva, a valorização da ambição pessoal, da confiança no esforço próprio, a importância do "impulso" ${ }^{\text {, }}$ do "anseio" de ter êxito. Por outro, um conjunto de reivindicações associadas com a democratização do laço social: aspirações de horizontalidade relacional que entram em choque com uma variedade de funcionamentos institucionais e interpessoais que as contradizem, particularmente condensadas nas experiências de abuso cuja denúncia é expandida. A perda da legitimidade das lógicas sistêmicas que ordenavam as relações sociais obriga à busca de formas, muitas vezes solitárias e nem sempre exitosas, de administrar as relações sociais, tanto simétricas como assimétricas. A interpenetração destes dois processos descreve uma condição histórica particular que se declina de maneira muito variada ao nível das experiências, segundo os distintos âmbitos da vida social. Alguns deles, em função de sua relevância para a argumentação, serão detalhados abaixo.

Para começar, encontra-se uma generalização do sentimento de desassossego entre os indivíduos, derivado da percepção que os espaços que ocupam são porosos e instáveis. A inconsistência posicional encontrada se define pelo sentimento de que todas as posições sociais podem sofrer processos ativos de desestabilização, o que implica uma "transferência" aos indivíduos da problemática do seu nível e tipo de integração social. Este traço está fortemente vinculado a fatores ligados a transformações econômicas (flexibilidade no âmbito laboral, endividamento), mas, também, a fatores políticos, urbanos e de contingências vitais, e constitui um fertilizante importante do "trabalho sem fim”, mandato e coerção que é o substrato central

5 Uma apresentação exaustiva destes resultados foi realizada em Araujo e Martuccelli (2012).

6 NT: no original, escrito entre aspas, "empuje". 
das experiências no mundo laboral. A flexibilização laboral, a competição generalizada entre assalariados e as transformações do sentido do trabalho, consequência da virada neoliberal, estabelecem o marco deste âmbito, caracterizando-se por grandes demandas temporais, trajetórias profissionais instáveis, culturas e ambientes de trabalho marcados por conflito e irritação, frustrações salariais e exigências altamente individualizadas de produção de sentido.

Em um contexto em que o trabalho sem fim se instala de fato como imperativo social, os indivíduos estão obrigados, ademais, a produzir uma articulação temporal das diferentes esferas da vida (família, associatividade, tempo livre). No que diz respeito às posições sociais ou ao trabalho, no que tange a temporalidade, cabe a eles tentar - ou não - articular estas tensões.

A justiça, por sua vez, especifica-se em torno do reconhecimento diferencial do mérito. Ao redor dele, constitui-se uma tensão entre o império crescente do ideal da competência e um conjunto de experiências sociais que colocam em questão a realidade deste princípio (p. ex. tráfico de influências, importância de adscrições). A prova do mérito submete, assim, os indivíduos a uma pressão individualista de novo tipo, a uma exigência de justiça mais pessoal que coletiva: a um sentimento de frustração que encadeia sem solução as experiências individuais e os juízos críticos dirigidos ao coletivo.

Por outro lado, e finalmente neste reconto, as expectativas de horizontalidade do laço social, as lógicas de competência e de usura que impõe o modelo econômico e produtivo, os novos conteúdos da concepção de justiça, complexificam os códigos e a legitimidade das lógicas interativas.

Nesse contexto, caracterizado pelo apoio escasso das instituições, os membros da sociedade são compelidos a se encarregarem de si mesmos, para se sustentar em sua individualidade. Os indivíduos são empurrados a serem atores no sentido mais forte do termo. Cada qual está impelido a produzir a consistência da posição social que ocupa, como também as hierarquias para o uso do tempo, as fronteiras ou os limites legítimos do consumo. Está demandado a desempenhos ${ }^{7}$ tão diversos como a autolimitação, o autocuidado, a sobrevivência material ou a produção de sentido, isto é, tem que se produzir como hiperator.

Os desafios estruturais evocados são comuns à sociedade chilena, porém, tomam um aspecto particular entre os membros dos setores populares. Para enfrentá-los, apoiando-se em tradições históricas, culturais e sociais já existentes, mas as ressignificando, os atores se veem compelidos em um contexto de depuração ideológica da individualidade, em que a referência ao coletivo se enfraquece ao construir perfis grupais e pessoais a partir de estratégias altamente individualizadas. O perfil da individualidade popular pode ser lido a partir de três grandes fatores que, sem serem os únicos, aparecem como especialmente relevantes, segundo o que encontramos.

7 NT: no original, llamado a rendimentos. 


\section{A individualidade popular e a força pessoal}

A primeira característica da individualidade popular é uma forma heroica de apresentação de si mesmo. Uma modalidade de individualidade de classe que se constrói assumindo o caráter estrutural da solidão e desproteção presentes na sociedade chilena, realidades diante das quais é preciso ter e desenvolver um "caráter" forte. Frente à profunda inconsistência das posições sociais, frente a todos os embates cotidianos da vida social, é preciso encontrar em si mesmo a força necessária para se sobrepor a elas. Essa experiência, indissociável de uma posição comum de classe, dá margem a uma expressão altamente individualizada da capacidade de seus membros.

\section{Tempo pessoal e respostas individuais}

Entre nossos entrevistados, uma expressão sintetiza melhor do que qualquer outra esta dimensão: "tenho um caráter bem forte". Ou seja, diante dos desafios da vida e da miríade de abusos cotidianos que isso implica, é preciso poder se afirmar nela e, para isso, a principal arma é o caráter. "Eu me considero como um macaco teimoso", disse-nos uma educadora social, "se quero algo, eu o consigo". Por meio de uma afirmação desse tipo, que se afirma um caráter bem temperado, verifica-se uma forma de consistência pessoal no seio de uma vida social que é permanentemente interpelada por inconsistências, transgressões e irresponsabilidades cotidianas.

Diante das dificuldades impostas pela sociedade, o caráter - ou o fato de ter um temperamento forte - aparece como um recurso importante para poder assumir uma atitude moral diante da vida, e para poder se defender nela. Para explicar, por exemplo, por que uma empregada doméstica que não se deixa intimidar por suas patroas, uma das entrevistadas evocou - como tantos outros - seu caráter: "É que só eu tenho meu caráter... Eu tenho um caráter especial, então, quanto eu não gosto de algo, eu saio". Uma confeccionista de roupa nos fez uma declaração similar: “Tenho caráter, se algo não me parece, não me parece... Para mim, a justiça é muito importante, o respeito pelas pessoas, pelo ser humano", o que faz com que ela - segundo disse - não se resigne à presença de maus-tratos ou abusos ao seu redor.

Sem dúvida, muitas destas asseverações não são provavelmente inteiramente certas. Como James C. Scott (2000) mostrou com contundência, os atores dominados tendem a adoçar a realidade de suas atitudes de resistência pública na ausência de seus superiores. É muito provável que nossos entrevistados sejam, na vida cotidiana, menos heroicos do que quiseram nos deixar entrever, mas o que interessa sublinhar é a linguagem empregada. A afirmação igualitária de si mesmo em e por meio das interações se apresenta como um assunto moral. Trata-se de uma exigência política de respeito e de uma questão de temperamento pessoal. Ou melhor, para as pessoas entrevistadas é também um assunto de temperamento porque requer um caráter forte para superar os desafios impostos pela vida cotidiana. 


\section{Caráter, abusos e autoridade}

Especialmente visível é o uso do recurso ao caráter nas relações com a autoridade ${ }^{8}$. A gestão das relações assimétricas resulta particularmente conflitiva devido a dois fatores que entram em colisão. Por um lado, a permanência de modalidades de exercício de poder desreguladas. Por outro lado, crescentes expectativas igualitárias, e de bom tratamento, visíveis hoje no Chile (POLITZER, 2006), ao ponto que, segundo um estudo de fim da década de 2000, um grupo de trabalhadores encostados na zona central do país indicou como elemento maior de satisfação laboral, depois da remuneração, o bom tratamento (39\%) (PNUD, 2009).

O importante é que o pedido de bom tratamento e a resistência ao abuso se apresentam como um assunto moral, e no fundo de temperamento. Aprendeu, nos disse um empregado, militante político, "a não permanecer calado. Me trouxe muitos problemas, mas me deixa mais tranquilo, ou seja, quando sinto uma coisa assim [uma injustiça], a digo, e não me seguro". O caráter como temperamento é mobilizado como suportes de uma atitude moral que, em sua ausência, e dada a rigidez dos vínculos verticais, teria, segundo os entrevistados, dificuldades em poder se expressar. A leitura, a denúncia e a resistência aos abusos são inseparáveis de uma interpretação em termos de caráter. Os indivíduos dos setores populares têm o sentimento de que devem se fazer respeitar pessoalmente em quaisquer universos sociais que não os respeitem institucionalmente.

Durante muito tempo, o fato de que os assalariados compartilham um mesmo universo de submissão laboral foi interpretado como um fator importante de produção de uma consciência de resistência coletiva. A transformação das condições de trabalho entre assalariados em uma mesma empresa modificou em profundidade essa situação (Soto, 2008; Ramos, 2009). Sem desaparecer do todo, a reinvindicação coletiva dá lugar a atitudes de resistência ou de adaptação mais individualistas. Os conflitos de interesses entre categorias sociais, sem desaparecer, dão lugar a conflitos intersubjetivos personalizados. Como comentou um trabalhador de construção: "Olha, o problema é que os caras (os chefes) tornam uma questão de afinidade, se lhes cai bem te tratam bem, deixam passar certas coisas, se no momento que reclamas e que o cara considera injusto isso que é reivindicado, então ele te deixa de lado, passa a implicar e começa a suspeitar".

A força pessoal aparece como um recurso indispensável para evitar o duplo obstáculo da verticalidade hierárquica presente no laço social e a horizontalidade desejada. A diferença estatutária entre uns e outros, entre os que mandam e os que obedecem, se espraia em um sentimento de desrespeito pessoal e, ao mesmo tempo, de um excesso estrutural do outro. $\mathrm{O}$ caráter forte como elemento de nivelação das relações não é só arma de defesa, é um estilo relacional e instrumento de compensação emocional, como mostra o caso em que, nos trabalhos dos grupos de conversação-dramatização, foi pedido para realizar teatralmente cenas da vida cotidiana, muitos atores dos setores populares expressaram o "prazer" que sentiram 
ao se localizar, durante o tempo limitado que durou a representação, no lugar do poder e de autoridade. A força pessoal "dos de baixo" é uma forte propriedade em evidência: fator de abuso e recurso de resistência.

Com certeza, esse elogio da força do caráter pessoal não os leva nunca a desconhecer totalmente a necessidade de suportes e ajudas diversas (ROBLES, 2000). Nesse sentido, o elogio do temperamento presente na individualidade no Chile é muito distinto do self-made man da tradição norte-americana (FISCHER, 2010), posto que está em geral associado menos à obrigação de participação em um coletivo e mais à valorização dos recursos relacionais que podem ser mobilizados em benefício desta vontade (LECHNER, 2006). Trata-se de apoios que, qualquer que seja sua realidade, os membros dos setores populares dizem encontrar menos em nível das instituições que em seus entornos sociais e familiares (VALENZUELA; TIRONI; SCHULLY, 2006).

No entanto, mesmo quando se reconhece a importância das relações e dado o custo humano que implica recorrer a elas (juízos morais, dúvidas), o que prima é uma forte valorização do caráter e de uma postura de solipsismo pragmático. O primeiro traço da individualidade popular, parcialmente compartilhado com outros setores sociais no Chile, mas aqui em proporções extremas, é que, na medida em que há que lidar sozinho, uma alta dotação energética como suporte à força resguarda a possibilidade de resistir aos embates do mundo. Embora esta atitude provavelmente não estivesse ausente no passado, por causa das mudanças estruturais produzidas nas últimas décadas, a força de caráter da individualidade popular não tende mais a se expressar em termos de consciência de classe, mas como um atributo pessoal.

\section{A habilidade e a oportunidade}

A esse primeiro fator, é adicionado outro, só em parte semelhante: o elogio da habilidade e da capacidade de aproveitar oportunidades (MARTUCCELLI, 2010). Em uma sociedade como a chilena, na qual, segundo os entrevistados, tem-se muitas vezes a dupla experiência por um lado, que tudo está bloqueado e, por outro, que tudo é inconsistente, o saber aproveitar as oportunidades é um imperativo pragmático. Para aproveitar a oportunidade, é preciso ter uma forma de inteligência que combine a sagacidade, a prudência, a ousadia, o "olfato", a atitude alerta, a desenvoltura, a finta. O importante é saber evitar obstáculos. Uma atitude tradicional ressignificada e valorizada nas últimas décadas, na medida em que o modelo neoliberal impôs o mérito e o anseio da mobilidade social como horizontes coletivos. Se esse traço idiossincrático está presente em quase todas as categorias sociais, é particularmente ativo entre os homens de setores populares. 


\section{O elogio da habilidade}

Verdadeira filosofia de vida, saber aproveitar a oportunidade é uma habilidade, contrariamente ao que muitas vezes se indica, profundamente otimista e individualista. A maneira pela qual, desde a inconsistência e a adversidade, muitos terminam tomando seu destino nas mãos. Um comerciante conta, por exemplo, como vai adaptando-se cotidianamente ao mercado, mudando seus produtos (frutas, têxtil, sapatos), desenvolvendo um estado permanente de alerta. No dia em que foi entrevistado, por exemplo, chovia, e lamentou não ter levado guarda-chuvas com ele para vendê-los aos entrevistadores. Uma postura que não é exclusiva do comércio. Muitos trabalhadores cultivam a atitude de estar sempre disponíveis às oportunidades laborais que podem se apresentar a eles (DÍAS; GODOY; STECHER, 2006).

No meio de uma sociedade na qual a dissimetria do poder é aguda (ARAUJO, 2009), as habilidades são uma maneira de introduzir a contingência na necessidade, de deixar aberto o horizonte do intercâmbio, de abrir uma janela a partir da qual coisas podem se dar de outra maneira. Os efeitos desse traço da individualidade são muitas vezes efêmeros, dado que as "estruturas" acabam prevalecendo sobre os "agentes". No entanto, o importante não está na inevitável restauração da ordem hierárquica, mas na permanente abertura das situações às quais a oportunidade dá uma filosofia de vida. Para ela, tem que ser vivo, rápido, astuto, estar alerta, mas também, e sobretudo, dado o conjunto de assimetrias existentes, ter flexibilidade para navegar entre todas essas escolhas. "Tem que ser faísca, que ser muito vivo, estamos vivendo no mundo dos vivos. Hoje em dia não podes parar, hoje em dia não podes confiar, hoje em dia tem que ser muito desperto, não ter dois olhos, ter quatro, não dois ouvidos, ter quatro, estar atento e que as oportunidades precisam ser tomadas, todas, porque não vão se repetir", explicou-nos uma empregada municipal, resumindo a maneira precisa dessa postura vital.

Vale a pena sublinhar: nessa valorização do oportunismo ecoa um imaginário igualitário. Ali onde tudo parece encerrado emerge, ainda que seja por um instante, a capacidade de alterar o rumo das coisas. A regra é simples: tem que saber aproveitar as oportunidades e, para isso, tem que estar ciente delas, pois são sinais que precisa saber decifrar e aproveitar. Essa característica da individualidade popular é indissociável de uma particular posição de classe. Porém, como no caso anterior, também se traduz em uma postura altamente individual.

\section{A moralidade do oportunismo}

No oportunismo, inclusive quando esse passa por uma transgressão, o importante é poder tirar proveito de um "golpe de sorte". O importante é saber interpretar os sinais da vida social, entrever as oportunidades para se afirmar como indivíduo. O importante é, assim, o estado de alerta no mundo, os sinais do mundo externo e não a introspecção. O golpe de sorte, a vivacidade, é um momento, não uma essência. O indivíduo se joga e volta a se jogar em cada um desses 
momentos. Daí a fé (não existe melhor termo) que se tem na "sorte". Verdadeiro culto popular, essa modalidade da "fé" permite compreender como é possível sustentar o sentimento de que, contra toda evidência, tudo pode mudar de repente. $\mathrm{O}$ azar é um horizonte permanente da vida. Alguns, como um carteiro, na verdade sentiram isso efetivamente, quando, por exemplo, anos atrás foi favorecido em um sorteio imobiliário, "eu tive essa sorte, salvei cinco anos de pagamento, isso foi um presente". O culto da sorte é uma esperança que não requer nenhuma prova tangível para sobreviver. Ao contrário, a denegação da realidade estimula sua força imaginária.

Mas a sorte não é o oportunismo. Se esse último geralmente pressupõe a primeira, para poder aproveitar a oportunidade se requer outra coisa além da mera sorte. Precisa ter gênio. Habilidade. A sorte é a sorte, mas fazer uso da oportunidade é um mérito. O oportunismo, cuja realização é geralmente exclusivamente individual, é, e aqui reside sua especificidade, um autêntico valor coletivo, ainda que sem dúvida ambivalente. A astúcia individualé profundamente celebratória e uma fonte de admiração tanto para si mesmo como para os outros, inclusive quando se suspeita de sua ineficiência a médio prazo.

$\mathrm{Na}$ oportunidade capturada, há um sentido particular de intensidade temporal. Não é que a ação oportunista se desinteresse do futuro, mas o júbilo do presente e do gesto obtido é um valor em si mesmo. Um pedreiro de construção nos contou como a oportunidade se deu anos atrás quando um amigo carteiro cedeu um pedaço de seu território. "Me tornei amigo do carteiro que me cedeu um pedaço do território dele porque tem quadrantes e me deu uma vila que também tinha, sempre me recordo, 289 casas, distribuía (as cartas) duas ou três vezes por semana e, mensalmente, me fazia entre 450 e 400 mil pesos naquele tempo, e eu mais que cobrar a carta, cobrava o serviço que entregava". Um bom "negócio" que requer, no entanto, sua "técnica". O negócio, nos explicou, é "um assunto de pele", razão pela qual às vezes ficava falando mais tempo do que o necessário com alguém, um tempo que depois se pagava no fim do mês: "Os carteiros têm manhãs. Por exemplo, existe um pacote que te incomoda, não o leva. Levam um aviso para que o venham buscar no correio. Eu levava esses pacotes... e, por exemplo, eu trouxe para a senhora, me via até três vezes, mas as três vezes lhe cobrava porque lhe deixava o aviso. São uma série de serviços que o usuário te paga”.

Vale a pena sublinhar que o imperativo de saber aproveitar a oportunidade não pode se exercer a qualquer preço. Aqui se traça, por sinuosa que seja, a linha de divisão com a transgressão. Diferentemente da transgressão da lei que pode, às vezes, ser percebida como uma manifestação do poder pessoal e de impotência coletiva, mas que, inseparável do abuso, gera tarde ou cedo rechaço, o oportunismo pode ser objeto de uma franca admiração. A distinção é sutil, mas tem sentido para muitos entrevistados. A primeira suscita em todo caso condenação: "Há mestres que querem ganhar o que vocês ganham em um mês em uma semana, em três dias, não eu, eu sou dos poucos que fazem bem o trabalho" (encanador); enquanto que o segundo, inclusive quando pode ser considerado como um vício coletivo, é sempre uma virtude pessoal.

9 NT: no original, "un asunto de piel". 
O elogio do oportunismo como elemento da individualidade popular opera, pois, dentro de uma gradação moral. Uma forma particular de excelência pessoal se revela ao ator a partir de uma versão particular da vontade, onde a "astúcia" prima. Um homem de 36 anos, encarnação estereotipada do "vivo", expressa-o ao evocar jocosamente um período de sua vida em que trabalhou fazendo mudanças. "Nas zonas de Las Condes, Lo Barnechea, Providencia... aí vivem pessoas quase ingênuas, mais velhas e são... mais abertas, lhe levávamos um colchão e, às vezes, nos davam pagamentos de cinco lucas ${ }^{10}$ ". Mas outras vezes, disse, "nós íamos aos apartamentos, subíamos vinte pisos, e nem um sinal de água nos davam”. Mau negócio. Para controlar essa contingência, desenvolveram uma "técnica": esticavam um assunto e ele, que era o "cérebro do assunto, começava a pechinchar uma gorjeta... e às vezes nos cansamos, sim, um dia de sexta, um dia de sábado, fazíamos por vinte lucas". O importante não é a quantia, é a esperteza ${ }^{11}$.

A característica que temos evocado o saber aproveitar a oportunidade em todas as circunstâncias é um traço maior da individualidade popular no Chile, um traço distintivo da fronteira moral própria desse grupo social e que, se o diferencia só em parte de membros das camadas médias, os distingue, sobretudo fortemente, dos membros de setores populares de outras sociedades (LAMONT, 2002). Nele, claro, são visíveis características do que pode ser denominado de um presentismo popular, uma atitude que não esqueçamos que foi e é muitas vezes estigmatizada como uma tara moral (LEWIS, 1982). No entanto, lido em outra chave, o oportunismo revela um indivíduo que realiza um exercício particular da vontade no seio de um contexto social percebido como hostil. O oportunismo é um mérito.

\section{Prazeres e irreverências vitais}

A terceira grande propriedade da individualidade popular é uma atitude jocosa, um tanto despreocupada, festiva diante da vida. Na verdade, trata-se de uma postura irreverente e zombeteira em relação às formas sociais instituídas, uma atitude bem analisada pelas ciências sociais desde Bakhtin (1974) destacou o papel do riso e, ainda mais, do humor, como traços centrais da peculiar maneira de enfrentar a vida dos setores populares. Um aspecto que, no entanto, tem traços peculiares no Chile e, por extensão, na América Latina, apesar das exceções (SALINAS, 1998, 2010), suficientemente sublinhadas. Um descuido tanto mais surpreendente que esta atitude está claramente presente em muitos dos grandes personagens do humor popular latino-americano: Cantiflas, Chaves ou Chapolin Colorado no México; Pepe Biondi e a lógica dos "bairros" na Argentina; Tulio Loza, o sábio migrante andino do Peru; o humor inconfundível de Condorito no Chile. Um frescor vital que se expressa de diferentes maneiras e em distintos âmbitos. Mas um frescor vital que mais que no ritual compartilhado (do carnaval ou na festa

10 Uma luca é o equivalente a mil pesos chilenos. NT: mil pesos chilenos equivalem, em dias atuais, aproximadamente a cerca de 5,50 reais.

11 NT: no original, golpe de mano. 
religiosa) se assenta em uma atitude própria e individual - um modo singular de enfrentar o mundo social. A capacidade de desfrutar "o momento" é percebida e valorizada como uma virtude pessoal.

\section{O picaresco espiritual}

Em primeiro lugar, essa característica da individualidade popular se expressa no domínio religioso. Sem que seja necessário estar de acordo, como Larraín (1996) sublinhou com razão, com os aspectos mais essencialistas da tese do substrato católico da identidade chilena, é preciso reconhecer a força decisiva desta matriz cultural na espiritualidade dos membros dos setores populares. A existência de uma cultura popular de conteúdo religioso é uma realidade ativa no Chile, muitas vezes associada a uma visão maternal, holística, barroca (MORANDÉ, 1984; PARKER, 1993; VÉLIZ, 1994). Se a espiritualidade dos setores populares compartilha muitos aspectos com aquela ativa em outros grupos sociais, possui, porém, uma característica distintiva: apresenta-se como uma variante engenhosa do picaresco. Nela, mesclam-se críticas irônicas à Igreja, com crenças altamente personalizadas da Virgem ou de Jesus Cristo.

Esta espiritualidade picaresca se expressou muitas vezes, por exemplo, através de anedotas mais ou menos jocosas. Uma trabalhadora do ramo dos calçados, que nos declarou que "rezava todas as noites", confessou por que, alguns anos atrás, afastou-se da Igreja. Ela nos disse que foi quando o padre Manolo, "que é bem bonito, por isso me lembrei, me disse 'pois veja como se vão os párocos e passa... o que está acontecendo? Então, disse a mim mesma que isso não valia a pena". O tom jocoso pode dar margem a relatos abertamente irreverentes: "Não vou à Igreja", nos disse uma empregada doméstica, "porque das vezes que fui acabei tendo um ataque de risos [ela ri]. Além disso, não mereço ir à Igreja todos os domingos para me benzer, porque... sou pecadora e, como fico rindo, prefiro não ir”. Em outros, a dependência da fé e dos mandamentos divinos não está isenta de certa manipulação moral. "Eu sou uma das pessoas que tem muito respeito a Deus, são valores muito fortes, porque faço coisas que não são condenáveis e, por exemplo, agora que estou só [seu marido está fora do país], fico orando para que me seja negada toda tentação carnal, porque sou humana", nos contou rindo outra empregada doméstica.

Este tipo de humor picaresco aparece em outros relatos, como no de uma educadora popular de crianças que conta que "já cheguei a pensar em ser freira, mas gosto muito mais dos homens [risos]... e não são coisas compatíveis". Um empregado de supermercado informou como participou ainda jovem, sobretudo por razões de amizade, de atividades de "uma igreja, os mórmons". E nos contou como progressivamente a bebida o fez sair “de perto da igreja”. Uma experiência a partir da qual guardou uma visão debochada dos crentes. Para nos convencer, conta: "Havia uma senhora que era evangélica e, quando fizemos uma festa em minha casa, 
fizemos uma cota de três $l u c a s^{12}$, e ela disse: 'Oh, mas eu não como carne, não como isto e não como aquilo'. Dissemos: 'Ah, não venha mais, já que se incomoda'. Porém, ela comeu igual, dançou e tudo mais... [risos]. Ela costumava dizer para minha mãe: 'Ouça, mas eu sou evangélica, posso dançar?'. Parecia um pião girando... [risos]”. Inclusive quando a fé produz mudanças importantes na vida pessoal, a experiência se narra em um tom alegre e aberto.

Sem dúvida, essa característica da individualidade popular não elimina outros aspectos da religiosidade popular, tanto no Chile como na América Latina, como, por exemplo, a importância das imagens, dos objetos ou dos talismãs na recriação da crença; como as formas peculiares de participação nas associações religiosas e seu uso tanto como rede de sociabilidade quanto como apoio informal; como o forte e plurissecular sincretismo espiritual e religioso (PARKER, 2005). Tudo isto é profundamente certo. Mas até mesmo neles, e em parte o motivo deles, é possível compreender este traço peculiar e jocoso, um tanto irreverente, da picaresca religiosa popular.

\section{A valorização do prazer vital}

Esse traço se manifesta, sobretudo, como uma filosofia leve e gozadora diante da vida. Uma modalidade de individualidade que em nossas entrevistas foi massivamente colocada em evidência, principalmente pelas mulheres dos setores populares. A distinção é suficientemente significativa para que nos seja possível distinguir entre, por um lado, um ethos popular individual feminino articulado preferencialmente ao redor do sentimento leve da vida e, por outro lado, como acabamos de ver no parágrafo anterior, de um ethos popular individual masculino que se organiza mais diretamente ao redor do oportunismo.

Nesse sentido, a sociabilidade masculina popular é também o teatro de situações de diversão sarcástica, de zombarias mútuas, de piadas - sobretudo, eróticas -, de convívio e de bebida; universos nos quais se expressa a intimidade, a confissão, nos quais se recebe o reconforto de uma frase brusca, mas cheia de apoio e coragem - uma sociabilidade cujas raízes históricas se encontram na experiência de mineiros e operários precários (SALAZAR; PINTO, 2002). Porém, essa sociabilidade masculina, em grande medida organizada em torno da bebida alcoólica, não tem geralmente a mesma leveza que se verifica nos testemunhos femininos.

Esta atitude vital, notemos, foi uma postura por muito tempo criticada por sua irresponsabilidade e até por sua imoralidade. Todavia, este julgamento mal disfarçado de classe não permite entender a consistência vital particular que se vincula a esta atitude: diante das adversidades incalculáveis da existência, o imperativo de aproveitar a vida é tudo menos um relaxamento. É um exercício espiritual permanente: aquele que valoriza não o presente, mas o que se rouba no presente da vida, a morte; aquele que não se deixa oprimir ou abater pelo 
infortúnio, porque sempre se pode ir a uma festa; aquele que quando tudo é obscuro, encontra, senão necessariamente a luz, ao menos o outro lado das coisas. Trata-se de um elemento moral alegre da individualidade popular. Aquele da vida leve ${ }^{13}$.

Como dar conta desta faceta entre os setores populares? À primeira vista, é possível ver nessa afirmação uma variante vernácula do individualismo romântico-identitário moderno, da importância concedida no seio da cultura do modernismo à autorrealização pessoal (BELL, 1982) ou, mais amplamente, a consolidação do que pode se denominar um consumismo vital. Essa interpretação deve ser, entretanto, descartada, já que a quase total ausência desse tema entre as camadas sociais mais permeáveis a este processo (as camadas médias) deve ser sublinhada.

Aqui também, o que esta atitude assinala é a presença entre os setores populares de um humor indissociável de uma experiência social comum do mundo e que se traduz em uma forte valorização da vida e do desfrute pessoal. A vida deve ser aproveitada. Diante da evidência da dureza da vida, o importante é aproveitar os momentos esporádicos e passageiros de alegria. Tomar a vida pelo lado bom. Tomar, sobretudo, o que a vida dá, quando vem e como vem. Uma posição muitíssimo menos presente nos setores médios e médios altos.

Nada de surpreendente, portanto, que a risada tenha aflorado com tanta naturalidade nas entrevistas realizadas. "Eu creio que a risada é o melhor para melhorar o espírito", aconselhou, rindo, uma trabalhadora da saúde. Os provérbios pregam este tipo de sabedoria vital, aqui como em outros casos (HOGGART, 1957). Uma empregada doméstica tratou de nos dar a fórmula: “Trato de ser alegre e não andar amarga, porque você tem que fazer a vida alegre... Quando você tem um problema surgindo, não sei, é que eu sou boa para rir, então quando tenho problemas trato de rir deles, às vezes fico com raiva, mas são muito raras as vezes... Como disse minha filha, andar triste envenena a alma”. A vida social, a verdadeira, a que se busca com afinco, é inseparável de um bom momento e saber rir é um necessário recurso pessoal. "O que eu gosto? Sair, ter amigos, conversar com minhas amigas, nos reunir com seus maridos... Adoro me encontrar com todo tipo de gente", conta uma encarregada de vendas que, pouco antes e pouco depois, contou-nos os maus tratos que sofreu durante anos por parte de seu marido. "Tenho um grupo aqui de minhas amigas que vão à capela, que são educadas para conversar, são régias, mas tenho um monte de velhas amigas que não te aconselho, que são safas, são boas para beber, para falar grosserias, e me sinto cômoda nos dois grupos, eu digo 'oh, que horror e me vejo tanto aqui quanto lá, porque eu não sou grosseira, não gosto de grosserias, claro, de repente eu também faço, mas geralmente não faço muitas grosserias... Mas eu me acabo de rir!”

13 NT: Vida fresca, no original. Para atender ao sentido dado pelos autores, optou-se por traduzir os termos fresco, frescura e suas variações por leve, leveza e palavras correspondentes da língua portuguesa, na medida em que a tradução literal daria margem para um sentido ambíguo inexistente no original espanhol. 


\section{O hedonismo como recurso individual}

Essa atitude indissociavelmente existencial e moral se sustenta a partir de uma certeza vital: "ninguém tira alguém da dança". "Ponha-se", confiou uma confeccionista de roupa, "ninguém vai atrapalhar a minha viagem a Chiloé, ao Valle del Elqui, ao la Luna". Uma atitude que é transparente na indulgência que os setores populares têm acerca dos seus filhos, a permissividade que às vezes outorgam à adolescência e à juventude, pois todos sabem que, depois, a vida será dura. A reprovação moral inverte o juízo do valor dominante. Alguns dizem, comentou-nos uma empregada do comércio, "quão bom é amadurecer (jovem), não, nada... se tem que desfrutar as etapas que correspondem", antes de defender a juventude como uma etapa legítima de diversão. Uma conviç̧ão transmitida inclusive como surpreendentes conselhos morais a seus filhos. Uma auxiliar de saúde comenta que disse a suas filhas que não se casem logo, "não, lhes digo, 'desfrutem a vida', lhes digo, a desfrutem. Sim, saiam com amigos, e conheçam amigos". Uma empregada doméstica foi ainda mais explicita. "Eu lhe disse [a minha filha] muito claramente [risos] 'não seja boba, não vai logo se apaixonar, primeiro estuda, conhece outros homens, mas não vai se apaixonar, ou se em qualquer momento me avisas, já converso de tudo, e ela me diz 'sim, mamãe, sim, eu entendo'”.

Por trás dessa leveza vital, é preciso ver no hedonismo do ethos popular individual feminino um ato político: a vontade de inscrever uma ação fora do domínio da impossibilidade, transformando o sentido de uma situação. Este hedonismo popular não é nem a desesperança dos pobres, nem a evasão dos marginais. É, na verdade, uma atitude ativa frente ao mundo. Uma postura que busca a vida plena nos momentos passageiros. Uma consciência de que sabe que a vida de todas as maneiras é e será dura, que as coerções são e serão ferozes, e que diante delas não há lugar nem para visões inutilmente heroicas, nem tampouco para representações exageradamente trágicas. Uma atitude que não é somente uma evasão, senão, ao contrário, uma maneira de dotar-se de um suplemento de prazer para poder suportar a existência. Os indivíduos não falaram nas entrevistas nem de evasão nem de compensação. Relataram, ao contrário, como cada um fez para extrair de si mesmos ativos e sustentos para aproveitar a vida como se pode, enquanto se pode, e a partir de onde está. "É que eu trato de fazer as coisas fáceis, não complico, é que já vivi uma vida complicada, então, para que seguir complicando a existência?", afirma uma dona de casa. Algo com o qual concorda uma feirante: "Evito ter muitos problemas, torno a vida leve. Se a vida é curta, é preciso tratar de vivê-la o mais leve possível", e também uma funcionária pública que resumiu com simplicidade: "É necessário viver a vida agradavelmente".

O hedonismo é uma gravidez não planejada que as camadas médias, presas em seu projeto de mobilidade social, tendem a julgar e condenar. É esta atividade vital que faz com que esta mulher, depois de sua longa jornada de trabalho, encontre as energias em algum lugar secreto, para sair e se divertir, "porque igualmente tenho que dar um tempo para mim mesma, né, [risos], não pode ser tudo do trabalho... Me alegro um pouco e não saio mais, no dia seguinte 
[domingo] eu tento dormir um pouco mais". A razão é simples, sorria: "Gosto de dança, me encanta”.

Para entender a especificidade existencial da individualidade popular, é preciso ir mais além de todo estereótipo de classe: aquele que condena desde sempre a irresponsabilidade perdulária das camadas populares, mas também aquele que louva a vida dos setores populares porque se divertem mais e melhor que as camadas médias. Em nossas entrevistas, essa atitude apareceu mais como um recurso individual fundado em um saber de que, se a vida é dura, é preciso poder também aproveitá-la. Uma maneira de viver - com intensidade e com humor a vida. Uma atitude que, aqui também, ressignifica a partir de um horizonte social particular, porém em chave individual, os imperativos da cultura do consumo imposta pelo modelo neoliberal (MOULIAN, 1997).

\section{Conclusão}

Durante muito tempo, as ciências sociais mobilizaram uma representação fortemente idealizada do sujeito popular, questionando a existência, se não necessariamente de individualidades, pelo menos de um apego a valores individualistas entre os setores populares. Muitas vezes, tratou-se de uma extrapolação generalizada, tanto em tempo como em espaço, de uma forma histórica e socialmente circunscrita da experiência popular - a da classe trabalhadora organizada e segmentada da Europa, ou de certos trabalhadores, como os mineiros. Uma generalização tanto menos justificada quanto que tendeu, incluindo nesse período e nessas sociedades, a minimizar fatores de divisão interna, como o racismo e outras formas de heterogeneidade e lutas de poder no seio dos setores populares (NOIRIEL, 1988; MERTON, 1987; ELIAS; SCOTSON, 1965), assim como sua porosidade a experiências sociais historicamente definidas. A noção de individualidade popular propõe uma interpretação de certas orientações de ação dos membros dos setores populares que sublinha, no marco de uma experiência como do mundo social atual, a afirmação crescente e progressiva de propriedades de individualidade entre eles. Sem desconhecer a permanência de outros elementos culturais, e até válido de uma certa identidade popular, comunitária ou de classe no Chile, a noção de individualidade popular destaca a especificidade do processo de afirmação individualizadora que se observa hoje entre seus membros.

A partir de um ponto de vista epistemológico, é próprio desta noção que se coloca em um nível mesossociológico romper, por um lado, com as grandes figuras macrossociais do sujeito ou da identidade popular (e suas supostas homogeneidades grupais) e, por outro, com a galeria interminável de retratos sociológicos ou de biografias (e a suposição de uma singularização meramente idiossincrática). A individualidade popular permite dar conta do modo com que a consciência de compartilhar experiências comuns "difíceis" e, muitas vezes, subalternas, abre caminho, no marco de recentes mudanças sociais, para tomadas de consciência em que, 
rompendo com antigos estereótipos culturalistas, consolidam-se tendências individualizadoras em termos de força pessoal, de habilidade e sentido de oportunidade e de prazer subjetivo.

\section{Referências}

ARAUJO, Kathya. Habitar lo social: Usos y abusos en la vida cotidiana en el Chile actual. Santiago: LOM Ediciones, 2009.

ARAUJO, Kathya. Experiencia social y metáforas espaciales. In: ETTE, Ottmar; NITSCHACK, Horst. (comps.). Trans ${ }^{\star}$ Chile: Cultura-historia-itinerarios-literatura-educación: Un acercamiento transareal. Madrid: Iberoamericana; Frankfurt: Vervuert, 2010. p. 38-58.

ARAUJO, Kathya; MARTUCCELLI, Danilo. Desafíos comunes: Retrato de la sociedad chilena y sus individuos. Santiago: LOM Ediciones, 2012.

BAKHTIN, Mikail. La cultura popular en la Edad Media y el Renacimiento. Barcelona: Barral, 1974.

BAROZET, Emmanuelle; ESPINOZA, Vicente. ¿De qué hablamos cuando decimos clase media? Perspectivas sobre el caso chileno. In: JOIGNANT, Alfredo; GÜELL, Pedro. (ed.). El arte de clasificar a los chilenos: Enfoques sobre los modelos de estratificación en Chile. Santiago: Ediciones Universidad Diego Portales, 2009. p. 103-130.

BELL, Daniel. Las contradicciones culturales del capitalismo. Madrid: Alianza, 1982.

BERNSTEIN, Basil. Langage et classes sociales. París: Minuit, 1975.

BOURDIEU, Pierre. La distinción. París: Minuit, 1979.

CATALÁN, Carlos; TORCHE, Pablo. Consumo cultural en Chile, miradas y perspectivas. Santiago: Instituto Nacional de Estadística y Consejo Nacional de la Cultura y las Artes, 2005.

CERTEAU, Michel de. L’invention du quotidien. Arts de faire. París: L'Union Générale d'Édition, 1980.

DÍAZ, Ximena; GODOY, Lorena; STECHER, Antonio. Significados del trabajo en un contexto de flexibilización laboral: la experiencia de hombres y mujeres en Santiago de Chile. In: DÍAZ, Ximena et al. (coord.). Trabajo, identidad y vínculo social. Santiago: Centro de Estudios de la Mujer, Universidad Diego Portales, 2006. p. 29-60. DUBIED, Annick; LITS, Marc. Le fait divers. París: Presses Universitaires de France, 1999.

ELIAS, Norbert; SCOTSON, John. The Established and the Outsiders. Londres: Sage, 1965.

ELIASOPH, Nina. Avoiding Politics: How Americans Produce Apathy in Everyday Life. Cambridge: Cambridge University Press, 1998.

FISCHER, Claude S. Made in America: A Social History of American Culture and Character. Chicago: University of Chicago Press, 2010.

FRANCO, Carlos. Imágenes de la sociedad peruana: La "otra" modernidad. Lima: Centro de Estudios para el Desarrollo y la Participación, 1991.

GARCÍA CANCLINI, Néstor. Culturas híbridas. México, DF: Grijalbo, 1990.

GERMANI, Gino. Política y sociedad en una época de transición: de la sociedad tradicional a la sociedad de masas. Buenos Aires: Eudeba, 1962.

GOULAT, Vincent. Médias et classes populaires: Les usages ordinaires des informations. París: INA Editions, 2010.

GRIGNON, Claude; PASSERON, Jean-Claude. Le savant et le populaire: Misé rabilisme et populisme en sociologie et en litté rature. París: Editions EHESS, Gallimard y Seuil, 1989.

GUTIÉRREZ, Horacio. Exaltación del mestizo: La invención del roto chileno. Revista Universum, Talca, Chile, v. 25, n. 1, p. 122-139, 2010.

HOGGART, Richard. A Local Habitation: Life and Times, 1918-1940. Londres: Chatto and Windus, 1988. 
HOGGART, Richard. The Uses of Literacy: Aspects of Working-Class Life with Special References to Publications and Entertainments. Londres: Chatto and Windus, 1957.

JAMES, Daniel. Resistencia e integración: El peronismo y la clase trabajadora argentina. Buenos Aires: Sudamericana, 1990.

LABOV, William. Sociolinguistique. París: Minuit, 1976.

LACLAU, Ernesto. La razón populista. Buenos Aires: Fondo de Cultura Económica, 2005.

LAMONT, Michèle. La dignité des travailleurs: Exclusion, race, classe et immigration en France et aux États-Unis. París: Presses de Sciences Po, 2002.

LARRAÍN, Jorge. Modernidad, razón e identidad en América Latina. Santiago: Editorial Andrés Bello, 1996.

LARRAÍN, Jorge. Identidad chilena. Santiago: LOM Ediciones, 2001.

LAVÍN, Joaquín. Chile: La revolución silenciosa. Santiago: Zig-Zag, 1987.

LECHNER, Norbert. Obras escogidas. Santiago: LOM Ediciones, 2006. $1 \mathrm{t}$.

LEWIS, Oscar. Los hijos de Sánchez. México, DF: Grijalbo, 1982.

MARTÍNEZ, Javier; PALACIOS, Margarita. Informe sobre la decencia: La diferenciación estamental de la pobreza y los subsidios públicos. Santiago: SUR, 1996.

MARTUCCELLI, Danilo. Dominations ordinaires: Explorations de la condition moderne. París: Balland, 2001.

MARTUCCELLI, Danilo. ¿Existen individuos en el Sur? Santiago: LOM Ediciones, 2010.

MARTUCCELLI, Danilo; SVAMPA, Maristella. La plaza vacía: Las transformaciones del peronismo. Buenos Aires: Losada, 1997.

MERTON, Robert K. Teoría y estructuras sociales. México, DF: Fondo de Cultura Económica, 1987.

MORANDÉ, Pedro. Cultura y modernización en América Latina: Ensayo sociológico acerca de la crisis del desarrollismo y de su superación. Santiago: Pontificia Universidad Católica de Chile, 1984.

MOULIAN, Tomás. Chile actual: Anatomía de un mito. Santiago: LOM Ediciones, 1997.

NOIRIEL, Gérard. Le creuset français: Histoire de l’immigration, XIXe-XXe siè cles. París: Seuil, 1988.

PARKER, Cristián. Otra lógica en América Latina: Religión popular y modernización capitalista. Santiago: Fondo de Cultura Económica, 1993.

PARKER, Cristián. ¿América latina ya no es católica? Pluralismo cultural y religioso creciente. América Latina Hoy, Salamanca, Espanha, v. 41, p. 35-56, 2005.

PNUD. Programa de las Naciones Unidas para el Desarrollo. Desarrollo humano en Chile: La manera de hacer las cosas. Santiago: PNUD, 2009.

POLITZER, Patricia. Chile: ¿De qué estamos hablando? Retrato de una transformació $\mathrm{n}$ asombrosa. Santiago: Sudamericana, 2006.

RAMOS, Claudio. La transformación de la empresa chilena: Una modernización desbalanceada. Santiago: Universidad Alberto Hurtado, 2009.

ROBLES, Fernando. El desaliento inesperado de la modernidad: Molestías, irritaciones y frutos amargos de la sociedad del riesgo. Santiago: RIL Editores, 2000.

SALAZAR, Gabriel; PINTO, Julio. Historia contemporánea de Chile. Hombría y feminidad. Santiago: LOM Ediciones, 2002. $2 \mathrm{t}$.

SALINAS, Maximiliano. En el chileno el humor vive con uno: El lenguaje festivo y el sentido del humor en la cultura oral popular de Chile. Santiago: LOM Ediciones, 1998.

SALINAS, Maximiliano. La risa de Gabriela Mistral: Una historia cultural del humor en Chile e Iberoamérica. Santiago: LOM Ediciones, 2010.

SANSOT, Pierre. Les Gens de peu. París: Presses Universitaires de France, 1991. 
SCHWARTZ, Olivier. Le monde privé des ouvriers: Hommes et femmes du Nord. París: Presses Universitaires de France, 1990.

SCHWARTZ, Olivier. Peut-on parler des classes populaires? La vie des idées, Paris, 13 set. 2011. Disponível em: http://www.laviedesidees.fr/IMG/pdf/20110913_schwartz.pdf.

SCOTT, James C. Los dominados y el arte de la resistencia. México, DF: Era, 2000.

SOTO, Álvaro. (comp.). Flexibilidad laboral y subjetividades: Hacia una comprensió n psicosocial del empleo contemporáneo. Santiago: LOM Ediciones, 2008.

SOTO, Hernando de. El otro sendero: La revolució n informal. Lima: El Barranco, 1986.

THOMPSON, Edward P. La formation de la classe ouvrière anglaise. París: Éditions de Maison des Sciences de l'Homme, 1988.

VALENZUELA, Samuel J.; TIRONI, Eugenio; SCULLY, Timothy R. (comp.). El eslabón perdido: familia, modernización y bienestar en Chile. Santiago: Aguilar, 2006.

VÉLIZ, Claudio. The New World of the Gothic Fox: Culture and Economy in English and Spanish America. Berkeley: University of California Press, 1994.

VERRET, Michel; CREUSEN, J. La culture ouvrière. París: L’Harmattan, 1995.

WEBER, Florence. Le travail à-côté: étude d’ethnographie ouvriè re. París: Institut National de la Recherche Agronomique, Éditions de l'École des Hautes Études en Sciences Sociales, 1989.

Recebido em: 30/12/2018

Aceito em: 30/12/2018 